2011-12-19

\title{
Developments in Performance Monitoring of Concrete Exposed to Extreme Environments.
}

\author{
W. J. McCarter \\ Institute for Infrastructure and Environment, Edinburgh, Scotland. \\ T. M. Chrisp \\ Institute for Infrastructure and Environment, Edinburgh, Scotland. \\ G. Starrs \\ Institute for Infrastructure and Environment, Edinburgh, Scotland.
}

See next page for additional authors

Follow this and additional works at: https://arrow.tudublin.ie/engschcivart

Part of the Structural Engineering Commons

\section{Recommended Citation}

McCarter, W. J. et al. Developments in performance monitoring of concrete exposed to extreme environments Published online Dec. 19th. 2011 in ASCE Journal of infrastructure systems doi:10.1061/(ASCE)IS.1943-555X.0000089

This Article is brought to you for free and open access by the School of Civil and Structural Engineering at ARROW@TU Dublin. It has been accepted for inclusion in Articles by an authorized administrator of ARROW@TU Dublin. For more information, please contact arrow.admin@tudublin.ie, aisling.coyne@tudublin.ie, gerard.connolly@tudublin.ie.

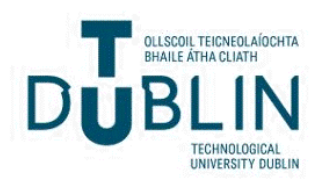




\section{Authors}

W. J. McCarter, T. M. Chrisp, G. Starrs, A. Adamson, E. Owens, P. A. M. Basheer, S. V. Nanukuttan, S. Srinivasan, and Niall Holmes 


\title{
Developments in Performance Monitoring of Concrete Exposed to Extreme Environments
}

\author{
W. J. McCarter'; T. M. Chrisp²; G. Starrs 3 ; A. Adamson"; E. Owens ${ }^{5}$; P. A. M. Basheer \\ S. V. Nanukuttan ${ }^{7}$; S. Srinivasan ${ }^{8}$; and N. Holmes ${ }^{9}$
}

\begin{abstract}
The performance of the surface zone of concrete is acknowledged as a major factor governing the rate of deterioration of reinforced concrete structures because it provides the only barrier to the ingress of water containing dissolved ionic species such as chlorides, which ultimately initiate corrosion of the reinforcement. In situ monitoring of cover-zone concrete is therefore critical in attempting to make realistic predictions as to the in-service performance of the structure. To this end, this paper presents developments in a remote interrogation system to allow for continuous, real-time monitoring of the cover-zone concrete from an office setting. Use is made of a multi electrode array embedded within cover-zone concrete to acquire discretized electrical resistivity and temperature measurements, with both parameters monitored spatially and temporally. On-site instrumentation, which allows for the remote interrogation of concrete samples placed at a marine exposure site, is detailed together with data handling and processing procedures. Site measurements highlight the influence of temperature on electrical resistivity and an Arrhenius-based temperature correction protocol is developed using on-site measurements to standardize resistivity data to a reference temperature; this is an advancement over the use of laboratory-based procedures. The testing methodology and interrogation system represent a robust, low-cost, and high-value technique that could be deployed for intelligent monitoring of reinforced concrete structures. DOI: 10.1061/(ASCE)IS.1943-555X.0000089. () 2012 American Society of Civil Engineers.
\end{abstract}

CE Database subject headings: Concrete; Monitoring; Electrical resistivity; Temperature effects.

Author keywords: Concrete; Cover zone; Sensors; Monitoring; Electrical resistivity; Arrhenius; Temperature.

\section{Introduction}

The premature deterioration of concrete highway structures because of corrosion of the steel reinforcement is a world wide problem. As in most developed countries, the infrastructure has

${ }^{1}$ Professor, Heriot Watt Univ., Institute for Infrastructure and Environment, School of the Built Environment, Edinburgh, EH14 4AS, Scotland, UK (corresponding author). E-mail: w.j.mccarter@hw.ac.uk

${ }^{2}$ Professor, Heriot Watt Univ., Institute for Infrastructure and Environment, School of the Built Environment, Edinburgh, EH14 4AS, Scotland, UK.

${ }^{3}$ Research Associate, Heriot Watt Univ., Institute for Infrastructure and Environment, School of the Built Environment, Edinburgh, EH14 4AS, Scotland, UK.

${ }^{4}$ Research Assistant, Heriot Watt Univ., Institute for Infrastructure and Environment, School of the Built Environment, Edinburgh, EH14 4AS, Scotland, UK.

${ }^{5}$ Senior Lecturer, Heriot Watt Univ., Institute for Infrastructure and Environment, School of the Built Environment, Edinburgh, EH14 4AS, Scotland, UK.

${ }^{6}$ Professor, Queen's Univ., School of Planning, Architecture and Civil Engineering, Belfast, BT7 1NN, Northern Ireland, UK.

${ }^{7}$ Lecturer, Queen's Univ., School of Planning, Architecture and Civil Engineering, Belfast, BT7 1NN, Northern Ireland, UK.

${ }^{8}$ Research Assistant, Queen's Univ., School of Planning, Architecture and Civil Engineering, Belfast, BT7 1NN, Northern Ireland, UK.

${ }^{9}$ Assistant Lecturer, Dublin Institute of Technology, Dept. of Civil Engineering, Bolton Street, Dublin, 1, Ireland; formerly, Research Associate, Queen's Univ., Belfast.

Note. This manuscript was submitted on June 24, 2011; approved on December 14, 2011; published online on December 19, 2011. Discussion period open until February 1, 2013; separate discussions must be submitted for individual papers. This paper is part of the Journal of Infrastructure Systems, Vol. 18, No. 3, September 1, 2012. (C) ASCE, ISSN 1076-0342/ 2012/3-167-175/\$25.00. now reached an age in which capital costs have decreased, but inspection and maintenance costs have grown, constituting a major part of the recurrent costs of the infrastructure. Life-cycle analysis estimates that indirect costs as a result of traffic delays and lost productivity resulting from bridge maintenance and superstructure replacement program are more than ten times the direct cost of corrosion (Yunovich et al. 2001). Demands for enhanced performance create a pressing need to be able to determine with an acceptable degree of confidence the anticipated/residual service life of concrete structures. Deterioration of reinforced concrete as a result of corrosion imparts a significant drain on bridge maintenance resources, not only in terms of the remedial work required but also in the costs associated with periodic inspections and testing together with the indirect costs noted previously.

Current testing methods tend to be intrusive, time-consuming, and costly, both in terms of the direct costs involved and in the indirect costs such as traffic management, road closures, and diversions required during inspection and testing. In the management of structures, monitoring the performance of the concrete could allow for the early detection of deterioration and thus assist in the implementation of appropriate repair strategies. The development of integrated monitoring systems for new reinforced concrete structures could reduce costs by allowing timely maintenance interventions and a more rational approach to the assessment of repair options and co ordination and the scheduling of inspection and maintenance program.

Integrated monitoring systems and procedures thus have an important role to play in the total management of structures as this involves both life-cycle cost and service-life calculations. When data from monitoring systems are used with improved service-life prediction models, additional savings in life-cycle costs could result, thus offsetting the up front installation costs of such monitoring systems. 


\section{Background}

Deterioration in concrete comprises an initiation period and a propagation period. The initiation period is characterized by changes that occur within the concrete cover zone in response to the exposure environment and continues until a stage is reached at which damage begins to propagate. The propagation period begins at a point in time defined when a particular event occurs (e.g., loss of steel passivity as a result of chloride ingress) and continues until a specified limit state is reached. The initiation and propagation stages of deterioration processes result from a complex interaction of physical, chemical, and electrochemical phenomena. A prediction of the field performance of reinforced concrete thus requires numerous data inputs, particularly, the response of the concrete to the changing ambient environment in the vicinity of a specific structural element or part of a structure. Currently, the most predominant process associated with concrete deterioration is the ingress of water contaminated with chloride ions. Chloride ions come from deicing salt used on roads for winter maintenance purposes or from the marine environment in which, for example, bridges span tidal estuaries. In addition, the extent of reinforcement corrosion, freeze thaw damage, sulfate attack, and alkali-silica reaction all depend on the availability of moisture.

Because it is the concrete cover zone that protects the reinforcing steel from the external environment (i.e., the surface $20-50 \mathrm{~mm}$ or so), the protective properties of this zone are crucial in attempting to make predictions as to the in service performance of the structure with regard to likely deterioration rates for a particular exposure condition and compliance with specified design life. The ability to continuously monitor the cover zone would thus allow for a more informed assessment of the current and future performance of reinforced concrete structures. The development and deployment of sensors and associated monitoring systems to assess cover-zone performance would form an important component in the inspection, assessment, maintenance, and overall management of reinforced concrete structures.

This paper presents developments in a monitoring system that could be exploited for the intelligent monitoring of reinforced concrete structures. In this context, intelligent monitoring is defined as "automated monitoring which explicitly provides information on current condition and deterioration rates to assist in predicting the remaining life of a component or structure" (Buenfeld et al. 2008). The focus of the work presented highlights the applicability of an embedded electrode array and associated remote monitoring system allowing interrogation from the office setting, thereby providing virtually continuous, real-time data on the performance of cover-zone concrete exposed to natural environments.

\section{Testing Methodology}

Regarding cover-zone properties, it is the permeation properties that are important, and terms such as diffusivity (moisture and ionic), permeability (air and water), and sorptivity are used in this respect (Basheer 1993). As a result, a number of surface-applied techniques have been developed and used to assess permeation properties, for example, the initial surface absorption test (ISAT) [British Standards Institution (BSI) 1996; Wilson et al. 1998]; Figg hypodermic methods (Figg 1973); water and air permeability tests (Meletion et al. 1992; Basheer 1993; Andrade et al. 2000b); the covercrete absorption test (CAT) (Dhir et al. 1987; Blight and Lampacher 1995); cumulative absorption and sorptivity methods (Hall and Yau 1987; BSI 2011; McCarter 1993). What has precluded their direct application in the field environment is their dependence on moisture distribution within the surface region
Table 1. Empirical Resistivity Thresholds for Depassivated Steel Reinforcement (Langford and Broomfield 1987; Broomfield 1997)

\begin{tabular}{lc}
\hline Resistivity $(\mathrm{k} \Omega-\mathrm{cm})$ & Probable corrosion rate \\
\hline$<5$ & Very high \\
$5-10$ & High \\
$10-20$ & Moderate/low \\
$>20$ & Low \\
\hline
\end{tabular}

just before testing. Many surface-applied, water absorption techniques also tend to be ultra-short in duration; for example, ISAT and CAT values are typically quoted after $10 \mathrm{~min}$ absorption (Classie et al. 1999). Furthermore, the depth to which surfaceapplied methods are assessed is unknown; in connection with rebar corrosion, it is the full cover depth that should be assessed (i.e., the surface $20-50 \mathrm{~mm}$ or so) and not just the surface few millimeter.

Because the flow of water under a pressure gradient (hence permeability) or the movement of ions under a concentration gradient (hence diffusivity) is analogous to the flow of electrical current under a voltage gradient, it is understandable that the electrical resistivity of the concrete (or its reciprocal, conductivity) could be of practical significance in assessing the durability of concrete structures (e.g., Andrade et al. 1993, 2000a; Polder and Peelen 2002; Shi 2004; Andrade 2010; Poursaee and Weiss 2010). Furthermore, once passivity is lost, research indicates that the single most important factor affecting the corrosion rate of the reinforcing steel is the resistivity of the surrounding concrete (e.g., Langford and Broomfield 1987; Alonso et al. 1988; Millard and Gowers 1992; Lopez and Gonzalez 1993; Fiore et al. 1996; Broomfield 1997; Brite-EuRam 1998; Gowers and Millard 1999); Table 1 presents empirical resistivity thresholds for depassivated steel.

\section{Remote Interrogation and Field Monitoring Program}

Remote (i.e., wireless) monitoring techniques, when used in conjunction with suitable sensor systems, have been developed and exploited in structural health monitoring applications to study, for example, vibration, deformation, and strain. In the work presented, this is extended to study the long-term performance of reinforced concrete.

\section{Electrical Measurements}

This study uses a multi electrode array (McCarter et al. 1996) that was embedded within the cover zone of concrete specimens and allowed for the monitoring of the spatial distribution of electrical resistance. Such measurements can be used to study water and ionic movement within the surface region (Raupach and Schiessl 2000; McCarter and Chrisp 2000; Chrisp et al. 2002; Rajabipour et al. 2005; Rajabipour and Weiss 2007). The array also had the facility to monitor temperature distribution through the cover region. In summary, the array comprised a series of electrode pairs mounted on a polyvinyl chloride (PVC), T-shaped former, with the former being secured onto two stainless-steel bars, as shown in Fig. 1(a). These bars allow for the attachment of the array to the reinforcement, and their length is tailored to suit the reinforcement detailing; the bars are electrically isolated from the steel reinforcement at the points of contact. Each electrode on the array comprised a stainlesssteel pin sleeved with insulation to expose a 5-mm tip; in each electrode pair, the pins had a (horizontal) center-to-center spacing 

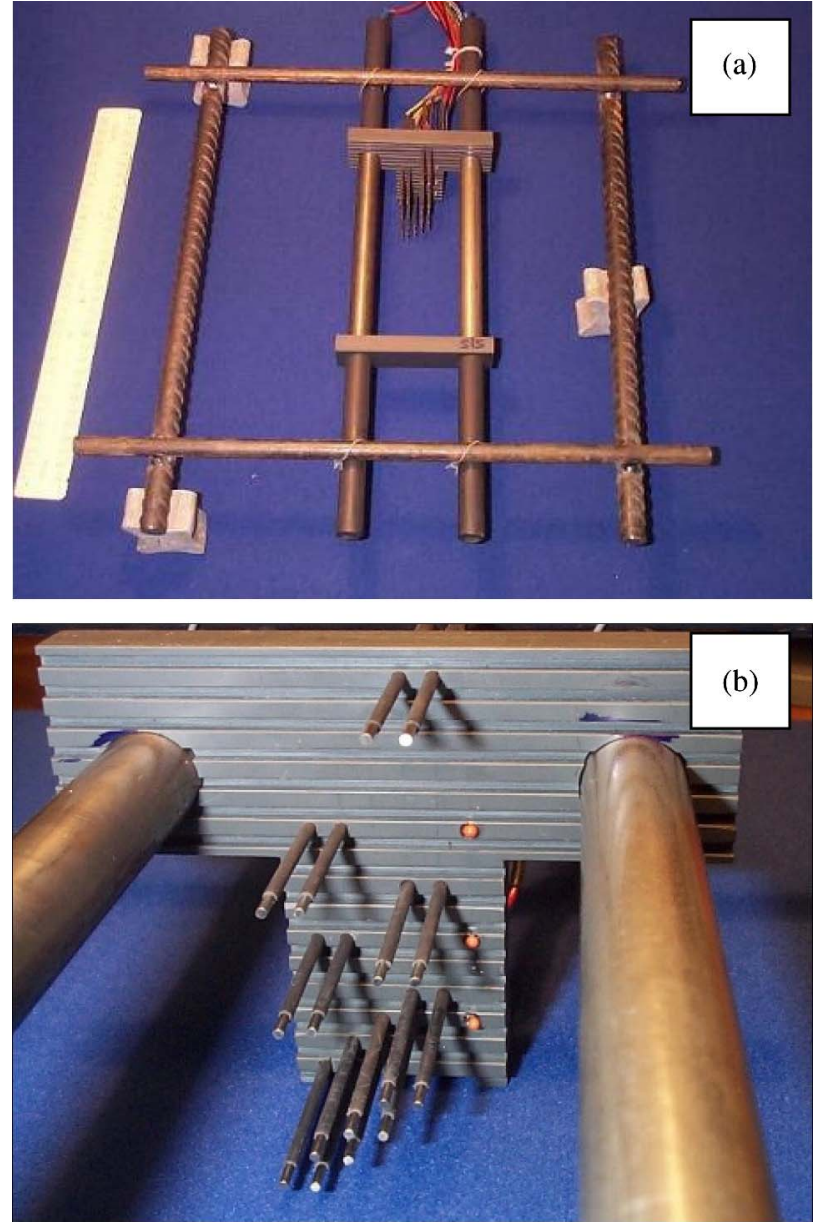

Fig. 1. Showing (a) the multi electrode array and rebar attachment facility; (b) the distribution of electrodes on the array

of $5 \mathrm{~mm}$. All stainless steel was marine grade 316 . The pairs of electrodes were positioned at discrete distances from the base of the former [Fig. 1(b)] and in this study, were located at 5, 10, $15,20,30,40$, and $50 \mathrm{~mm}$ from the concrete surface; four thermistors were also mounted on the former and positioned at 10, 20, 30 , and $40 \mathrm{~mm}$ from the concrete surface to enable temperature measurement. Before installation, the electrodes on the array were calibrated in solutions of known resistivity, thereby enabling the measured resistance, $R$ (in ohms), to be converted to resistivity, $\rho$ (in ohm-cm), or conductivity, $\sigma$ (in $\mathrm{S} / \mathrm{cm}$ ), hence

$$
\rho=\frac{1}{\sigma} K R \quad \text { ohm }-\mathrm{cm}
$$

where $K=$ calibration factor for the array, which was $1.25 \mathrm{~cm} \pm 5 \%$ and represented an averaged value over the electrode pairs; values presented for each electrode pair are thus within this range of scatter.
Electrical resistance measurements were obtained using an auto ranging logger that measured the resistance of the concrete between each electrode pair using an A.C. voltage of amplitude $1.0 \mathrm{~V}$ at a fixed frequency of $1 \mathrm{kHz}$. Previous studies indicated that the chosen operating voltage and frequency would ensure electrode polarization effects were minimized (McCarter and Brousseau 1990). Thermistor measurements were also acquired using the same system. The logger served a dual purpose because it also acted as the system controller, further details of which are presented subsequently.

\section{Materials and Specimens}

In the current trial work, concrete specimens were exposed to a marine environment to include the spray, tidal, and submerged zones. Concrete mixes were chosen to satisfy the requirements for all exposure conditions specified in BS-EN 206-1:2000 (BSI 2000b) and are presented in Table 2. Dredged river gravel and matching fine aggregate were used; the binders comprised CEM I 42.5N portland cement (PC) to BS-EN197-1:2000 (BSI 2000a); CEM I cement blended with ground granulated blastfurnace slag (GGBS) to BS-EN15167-1:2006 (BSI 2006b); and CEM I cement blended with fly ash to BS-EN 450-1:2005 (BSI 2005). Specimens were $300 \times 300 \times 200 \mathrm{~mm}$ (thick) slabs, with the working face cast against plywood formwork. An array, similar to that described previously, was placed at the plan center of each slab, although the stainless-steel bars were replaced with two 15-mm-diameter, mild-steel ribbed reinforcing bars positioned within the slab at a distance of $50 \mathrm{~mm}$ from the exposed surface, as shown schematically in Fig. 2(a). The cut ends of the rebar were coated with epoxy and also had a 50-mm cover. Electrical connections were made to these bars to allow for half-cell potential measurements. On demolding, the samples were wrapped with damp hessian and polythene for a period of seven days. All surfaces, apart from the surface cast against the formwork, which was the exposed working surface, were then sealed with several coats of an epoxy-based paint to ensure one-dimensional (1D) moisture and ionic movement. Cabling from the array was color coded and taken into a watertight glass-reinforced plastic (GRP) enclosure placed in the face opposite to the working face; a 37-pin, multi pole female D connector was used to terminate all wires. The seal on the lid of the GRP box had been pressure tested to $1 \mathrm{MPa}$ to ensure watertightness under a hydrostatic head. Fig. 2(b) displays a slab with the lid removed to show the GRP enclosure and 37-pin D connector.

A total of 18 specimens of each mix were transported and placed at a marine exposure site on the Dornoch Firth (Scotland) [Fig. 3(a)] and secured in galvanized steel frames [Fig. 3(b)]; six specimens per mix were positioned at three exposure environments (BSI 2000b, 2006a) as follows: (1) above high-water level in the airborne spray zone, classed as XS1 exposure; (2) just below highwater level in the tidal/splash zone, classed as XS3 exposure; and (3) below midtide level, classified as the submerged zone, $\mathrm{XS} 2$ exposure.

Table 2. Concrete Mixes Used in Site Trials

\begin{tabular}{lcccccccc}
\hline Mix designation & $\begin{array}{c}\text { PC } \\
\left(\mathrm{kg} / \mathrm{m}^{3}\right)\end{array}$ & $\begin{array}{c}\text { GGBS } \\
\left(\mathrm{kg} / \mathrm{m}^{3}\right)\end{array}$ & $\begin{array}{c}\text { Fly ash } \\
\left(\mathrm{kg} / \mathrm{m}^{3}\right)\end{array}$ & $\begin{array}{c}20 \mathrm{~mm} \\
\left(\mathrm{~kg} / \mathrm{m}^{3}\right)\end{array}$ & $\begin{array}{c}10 \mathrm{~mm} \\
\left(\mathrm{~kg} / \mathrm{m}^{3}\right)\end{array}$ & $\begin{array}{c}\text { Fine } \\
(<4 \mathrm{~mm})\left(\mathrm{kg} / \mathrm{m}^{3}\right)\end{array}$ & $\begin{array}{c}\text { WR } \\
\left(\mathrm{l} / \mathrm{m}^{3}\right)\end{array}$ & $\begin{array}{c}F_{28} \\
(\mathrm{MPa})\end{array}$ \\
\hline CEM I 42.5N & 460 & - & - & 700 & 350 & 700 & 1.84 & 0.4 \\
CEM III/A & 270 & 180 & - & 700 & 375 & 745 & 3.60 & 0.44 \\
CEM II/B-V & 370 & - & 160 & 695 & 345 & 635 & 2.65 & 0.39 \\
\hline
\end{tabular}

Note: $\mathrm{WR}=$ water reducer; $\mathrm{w} / \mathrm{b}=$ water-binder ratio; $F_{28}=28$-day compressive strength. 


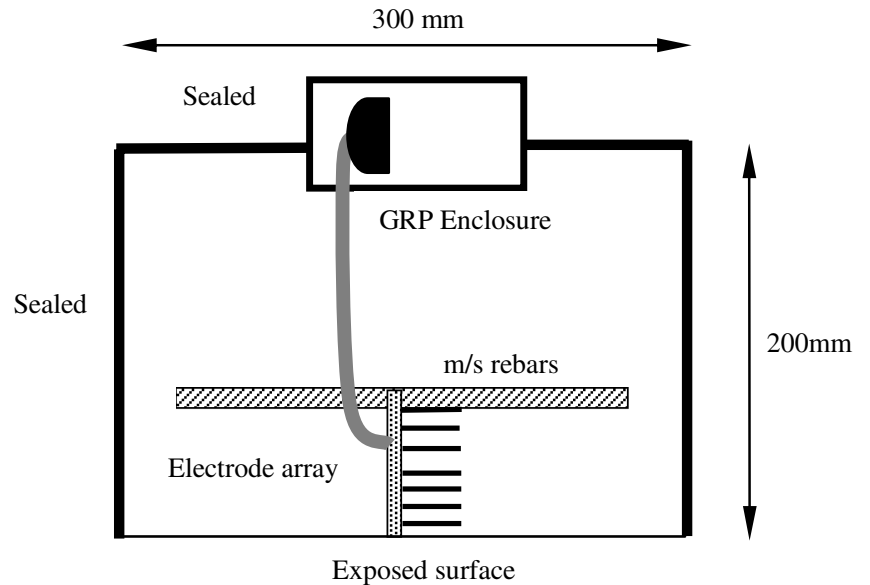

(a)

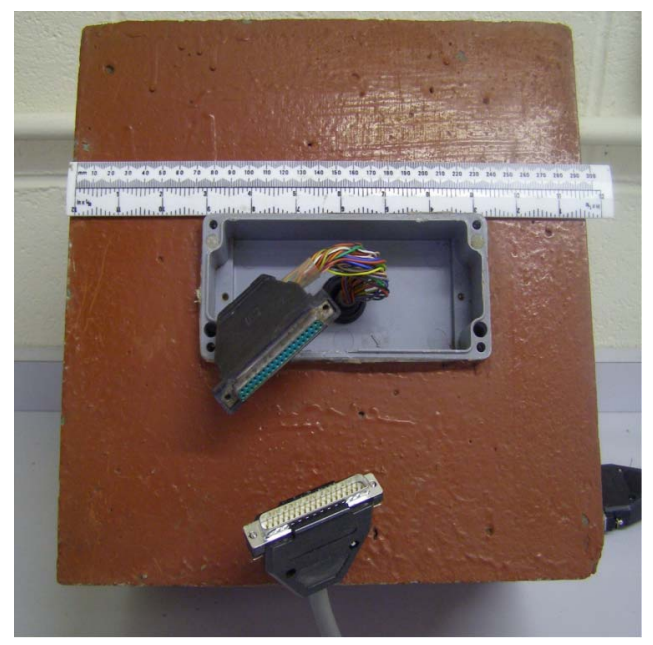

(b)

Fig. 2. Schematic diagram of (a) embedded array and cable termination; (b) GRP enclosure and lead termination at a 37-pin D connector

\section{Remote Monitoring of Cover-Zone Response}

During the early stages of the study, site visits were required, with measurements on the specimens recorded manually; however, because of the remoteness of the site, data collection was erratic with little data obtained because of the placement of the samples in 1998. Clearly, to gain a more informed understanding as to how the cover-zone concrete was/is performing and its response to changing environmental conditions, the periodicity of data collection needed to be increased. As a consequence, the authors developed a system to allow for remote interrogation of the specimens, thereby virtually providing a continuous feedback of site data and eliminating the need for site visits. This system has been under trial since November 2010.

In the current trial, a total of six samples were hard wired back to the interrogation system (described subsequently) by means of individual multi core cables: three samples, one of each mix, at the XS2 environment and a corresponding number at the XS3 environment. In summary, 37-pin, male D connectors were secured at the ends of the connecting cable; one end was connected to the interrogation system and the other end connected to the female $\mathrm{D}$ connector on the sample. The entire male-female connection [see Fig. 2(b)] at the sample end was sealed in the GRP box by flooding the box with an epoxy-based potting compound.

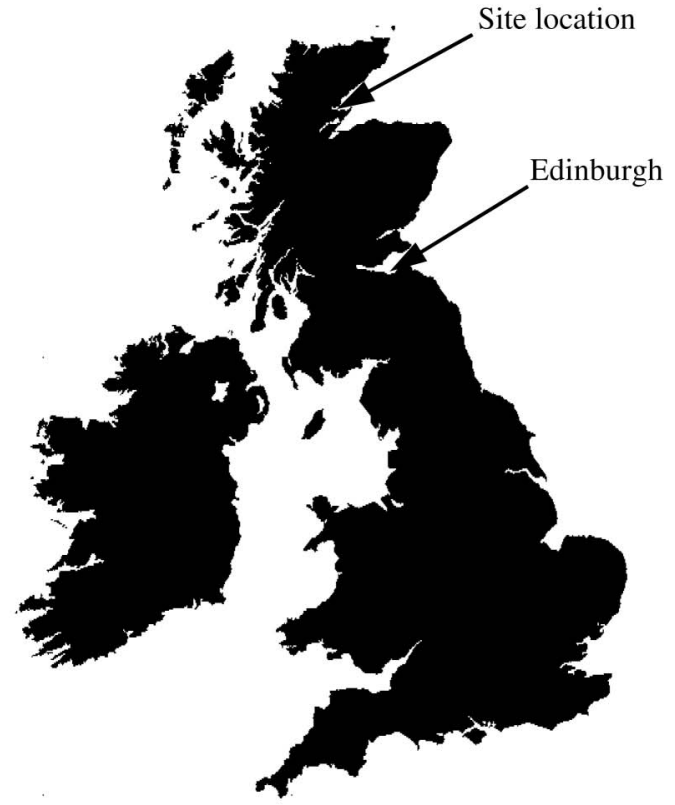

(a)

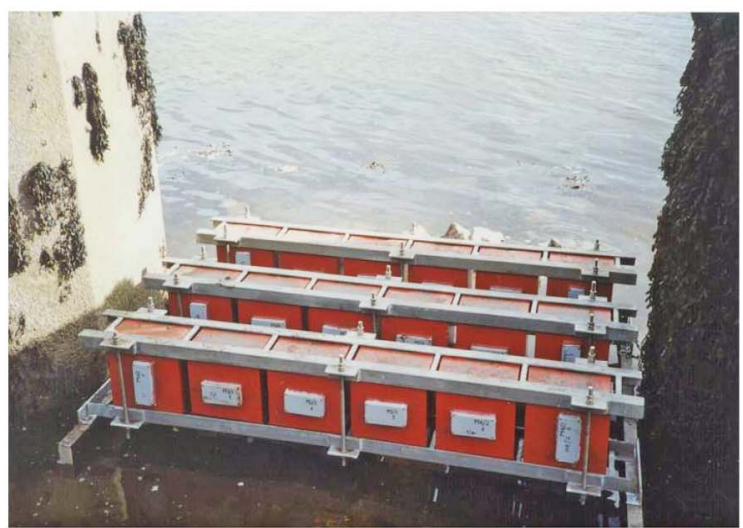

(b)

Fig. 3. (a) Location of marine exposure site; (b) slabs secured in galvanized steel frames showing the GRP enclosures

The interrogation facility at the exposure site comprises two watertight enclosures [Fig. 4(a)] secured to a concrete pier stem, the latter forming part of another related research program (Nanukuttan et al. 2008). One enclosure contains a multiplexing unit [Fig. 4(b)]; the other contains the controller and resistance measurement circuitry [Fig. 4(c)]. The multiplexing unit and controller are permanently connected. The cabling from the embedded arrays was connected to the multiplexing unit in Fig. 4(b), with a total of six samples connected to the unit in this trial. The communications interface with the controller is provided by a modem using a dial-up approach and a computer mounted software utility to establish a data connection to the modem, effectively creating a transparent link between the office-based computer and the serial port on the site-based system controller. Data are recovered in the same way as a direct RS232 connection using standard ASCII commands by means of the computer's modem. The controller is accessed through the mobile telephone network [Fig. 4(d)], and the entire system is powered by a battery that is trickle charged using a solar panel [Fig. 4(d)]. The time interval between measurement cycles is configured remotely from the office and in this current trial, is set on a 12-h cycle. 
(b)

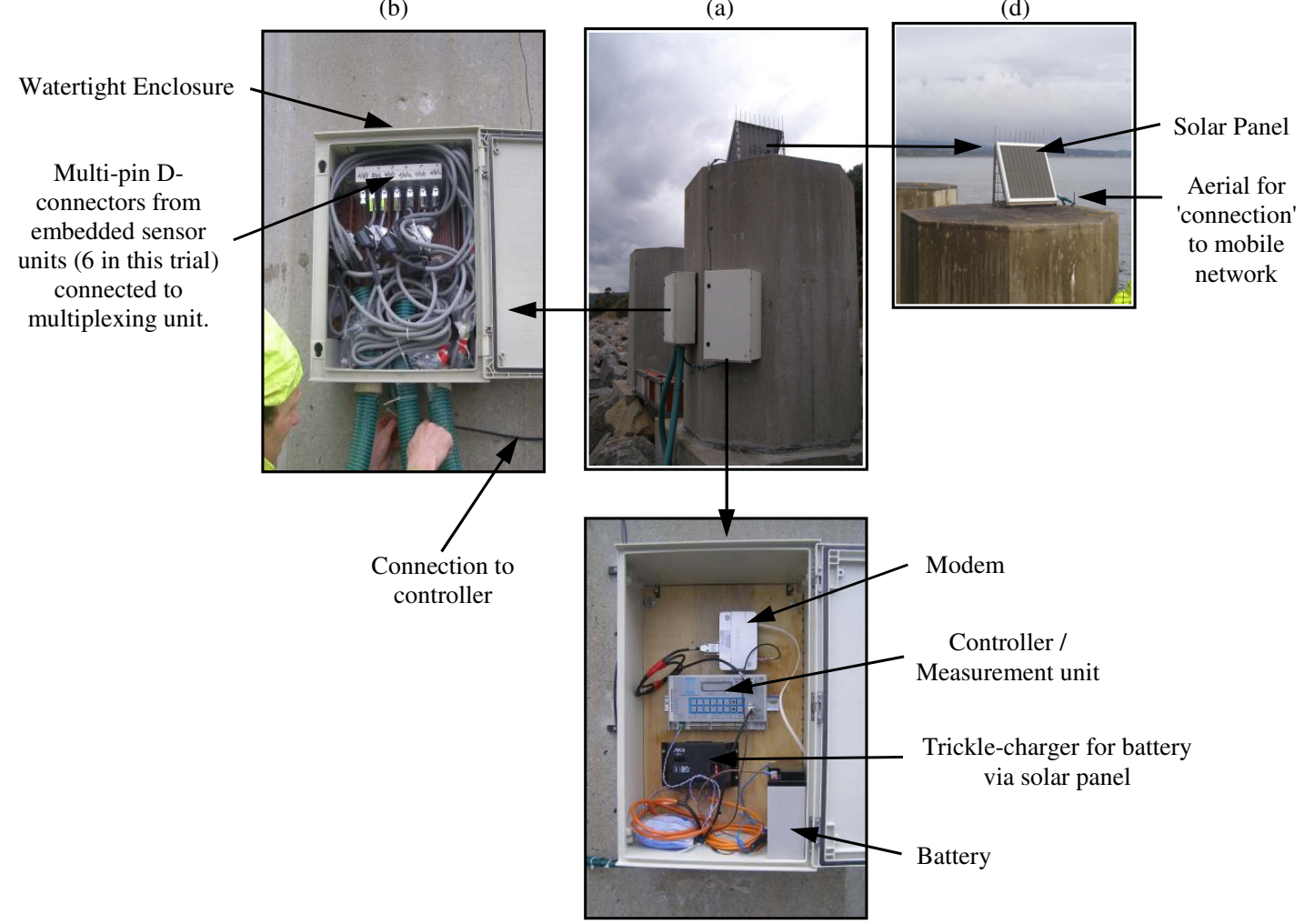

(c)

Fig. 4. (a) Watertight enclosures for monitoring and telephony equipment; (b) termination of cabling from sensors at multiplexing unit; (c) combined system controller/measuring unit, battery, and trickle charger from solar panel; (d) solar panel and aerial for wireless connection

During a measurement cycle, cover-zone resistance and thermistor data are recorded for all embedded arrays, with each array returning seven resistance and four thermistor measurements that are subsequently stored by the controller. The systems then sleeps until the next measurement sequence is triggered by the controller. By operating in a wake/sleep mode, the overall power consumption is reduced by drawing minimal current between logging events. For the modem to answer calls, it must be powered continuously but only draws about $10 \%$ of full power when not actively communicating. The data carrier detect line on the modem serial port is used to wake up the controller when an incoming data connection is detected (i.e., the system is interrogated from the office). The data stored by the controller can be accessed and downloaded at any time. If the storage capacity of the controller is exceeded, a warning is returned to the office. All measurements are returned from site as a Microsoft Excel spreadsheet, which allows for the ease of data manipulation and is discussed subsequently.

\section{Results and Discussion}

This section highlights data handling and processing protocols and presents data taken over the initial 150-day period after the installation of the remote interrogation. Because of the considerable number of measurements collected, only typical measurements are presented for illustrative purposes. For clarity, only every fifteenth data marker is presented in these figures.

\section{Resistivity Measurements}

Figs. 5(a-c) present the variation in cover-zone resistivity (in $\mathrm{k} \Omega-\mathrm{cm}$ ) for the three concrete mixes at the XS2 environment [i.e., below mid-(c) tide level] over the initial 150-day period after the installation of the remote interrogation system. Over the period presented (November-March), it is clear that the resistivity of the samples with replacement materials [Figs. 5(b and c)] is significantly greater than that of the samples with plain portland cement binder [Fig. 5(a)], the relevance of which is discussed subsequently, and also that the resistivity of the samples fluctuates markedly over the test period; it is evident that these fluctuations occur at similar times in all concrete mixes.

Regarding the resistivity of the samples, discussed in the preceding paragraph, above, because electrical conduction through concrete will be dominated by ionic conduction effects by means of the continuous pore network between the electrodes it will, as a consequence, be temperature dependent (Whittington et al. 1981; Castellote et al. 2002). Whereas in the laboratory, ambient temperature can be controlled, this is not the case for concrete exposed to the natural environment, in which the temperature can vary markedly. The following discussion outlines a protocol to standardize in situ resistivity measurements to a reference temperature. This is of considerable importance if the methodology is to be exploited as a viable monitoring procedure because it is essential to distinguish between changes in resistivity as a result of temperature and changes caused by wetting/drying action and ionic ingress.

\section{Cover-Zone Temperature}

Thermistor measurements were converted to temperature using the Steinhart-Hart equation:

$$
T=\left[A+B \ln R+C(\ln R)^{3}\right]^{-1}-273.15
$$

where $R=$ measured resistance of the thermistor (ohms); $T=$ temperature $\left({ }^{\circ} \mathrm{C}\right) ; A, B$, and $\mathrm{C}=$ coefficients, which depend on 

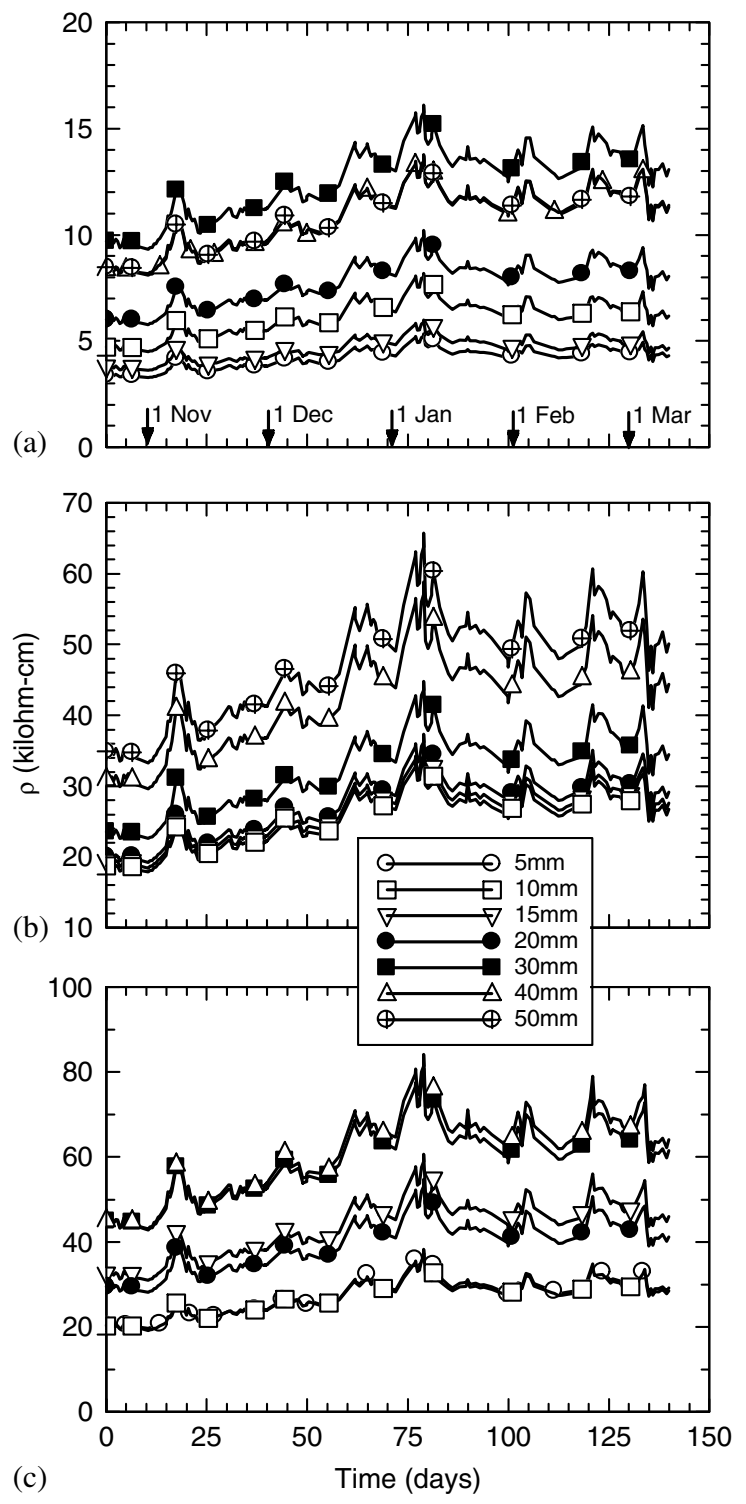

Fig. 5. Temporal and spatial variation in resistivity for (a) CEM I concrete mix; (b) CEM III/A concrete mix (Note: data lost for 5-mm depth); (c) CEM II/B-V [Note: in (c), the curve for $50 \mathrm{~mm}$ is omitted for reasons of clarity because values are $>100 \mathrm{k} \Omega-\mathrm{cm}$ ]

the type of thermistor; and $\ln =$ natural logarithm. For the thermistors used in the current work, $A, B$, and $C$ were $1.28 \times 10^{-3} \mathrm{~K}^{-1}$, $2.36 \times 10^{-4} \mathrm{~K}^{-1}$, and $9.31 \times 10^{-8} \mathrm{~K}^{-1}$, respectively.

Fig. 6 displays the variation in the mean cover-zone temperature (determined from the four thermistor values) for the concrete mixes presented in Fig. 5. It is apparent that the resistivity fluctuates in sympathy with the changing temperature, and it is important to distinguish between changes in resistivity as a result of temperature effects and changes in resistivity as a result of ionic ingress, changing levels of moisture content, or hydration effects; considering the age of the specimens, however, the influence of hydration is negligible.

An Arrhenius relationship is used to model the influence of temperature on resistivity as follows:

$$
\rho=\rho_{o} e^{\left[\frac{E_{a}}{R_{g} T_{k}}\right]}
$$

where $\rho=$ resistivity $(\mathrm{k} \Omega-\mathrm{cm}) ; T_{K}=$ absolute temperature $(\mathrm{K})$; $\rho_{\mathrm{o}}=$ pre-exponential constant $(\mathrm{k} \Omega-\mathrm{cm}) ; R_{g}=$ gas constant

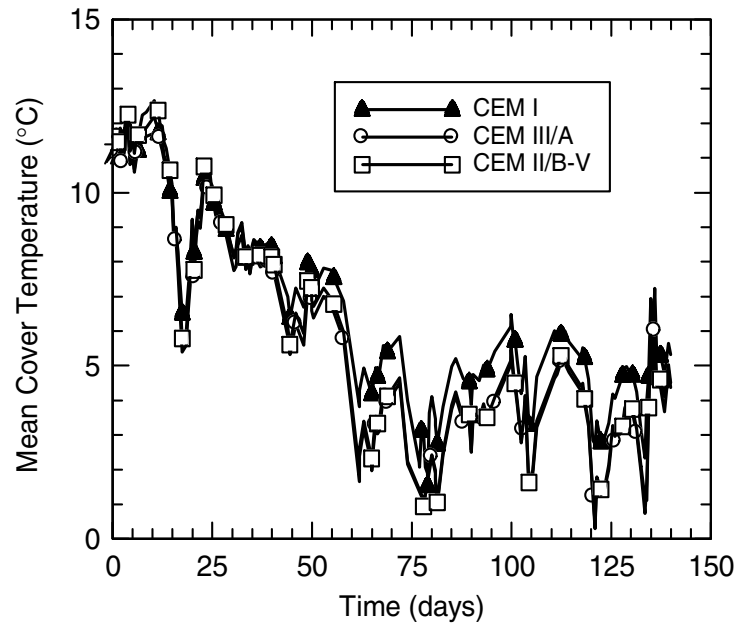

Fig. 6. Variation in (mean) cover-zone temperature for concrete mixes

$\left(8.3141 \times 10^{-3} \mathrm{KJ} / \mathrm{mole} / \mathrm{K}\right)$; and $E_{a}=$ activation energy for conduction processes in concrete $(\mathrm{kJ} / \mathrm{mole})$. If $\rho_{x}$ and $\rho_{y}$ are the resistivity measurements at temperatures $T_{k, x}$ and $T_{k, y}$, respectively, then, from Eq. (3):

$$
\rho_{x}=\rho_{y} e^{\frac{E_{a}}{R_{g}}\left[\frac{1}{T_{k, x}}-\frac{1}{T_{k, y}}\right]}
$$

From Eq. (4), a value of resistivity, $\rho_{y}$, recorded at a temperature, $T_{k, y}$, could then be used to obtain an equivalent resistivity, $\rho_{x}$, of the material a temperature, $T_{k, x}$, through a knowledge of the $E_{a} / R_{g}$ ratio for the conduction process. This formalism enables measurements to be standardized to a reference temperature, thereby removing the influence of temperature on electrical resistivity. In the current work, the reference temperature $\left(T_{k, x}\right)$ is taken as $25^{\circ} \mathrm{C}(298.15 \mathrm{~K})$.

\section{Evaluation of $E_{a} / R_{g}$ from In Situ Measurements}

The ratio $E_{a} / R_{g}$ for the concrete between each pair of electrodes on the array can be obtained from the in situ measurements and allows for the evaluation of this parameter for a particular concrete mix and electrode pair. Eq. (3) can be written as

$$
\ln \rho=\ln \rho_{\mathrm{o}}+\frac{E_{a}}{R_{g} T_{k}}
$$

Hence, the plot of $\ln \rho$ versus $1 / T_{k}$ will be a straight line of slope $E_{a} / R_{g}$. This value is then used in Eq. (4) to standardize the resistivity values to $25^{\circ} \mathrm{C}$. Using in-situ site measurements are more relevant than a determination of this value form controlled laboratory tests.

As way of illustration, Fig. 7 presents the resistivity values in Fig. 5(a) for the CEM I concrete mix plotted against the mean cover-zone temperature in the format of Eq. (5) for data obtained over a period of 150 days. The $E_{a} / R_{g}$ ratio (slope) obtained from these curves and the calculated activation energy $\left(E_{a}\right)$ at each electrode pair are presented in Table 3; for comparison, the respective values obtained for the other mixes are presented.

Having obtained values for the $E_{a} / R_{g}$ ratio, the measured resistivity can now be standardized to the reference temperature using Eq. (4) at each electrode pair on the array. Figs. 8(a-c) display the measurements standardized to the reference temperature of $25^{\circ} \mathrm{C}$ for the concrete mixes. Because the resistivity remains virtually constant over the test period, the fluctuations in resistivity measurements displayed in Fig. 5 are entirely caused by changes in temperature. This also indicates that the Arrhenius approach is adequate in 


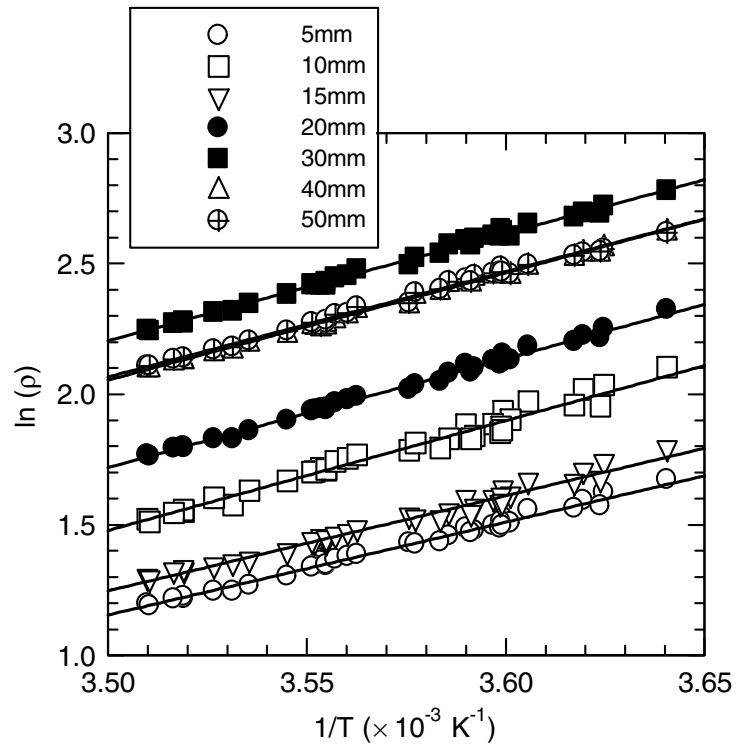

Fig. 7. Data in Fig. 5(a) plotted in Arrhenius format

explaining the influence of temperature on electrical resistivity measurements and could be used as a procedure for standardizing field data.

\section{Significance of Resistivity Measurements in Performance Monitoring}

As noted in the introductory section, the permeability, diffusivity, and electrical resistivity of concrete are inter related, which makes the measurement of this parameter a simple yet effective way to study the performance of concrete. To illustrate this, the NernstEinstein equation (Atkinson and Nickerson 1984; Garboczi and Bentz 1992; McCarter et al. 2009) relates the diffusion coefficient of a porous material, $D_{\text {eff }}$, and resistivity through the following relationship:

$$
\frac{D_{\text {eff }}}{D_{o}}=\frac{\rho_{p}}{\rho_{\text {bulk }}}=\tau
$$

where $\tau=$ tortuosity; $\rho_{\text {bulk }}=$ bulk resistivity of the saturated material; $\rho_{p}=$ resistivity of the interstitial pore fluid; $D_{o}=$ diffusion coefficient of the desired ion in pure water (e.g., the $D_{o}$ value for chloride in pure water is $2.032 \times 10^{-9} \mathrm{~m}^{2} / \mathrm{s}$ ). Hence, a measurement of electrical resistivity gives an indirect assessment of diffusivity and could allow the performance concretes to be ranked. Those electrodes on the array positioned furthest from the concrete surface (i.e., at $50 \mathrm{~mm}$ ) could be exploited in this respect.

The bulk resistivity of the concrete, $\rho_{\text {bulk }}$, noted previously, will be directly related to the tortuosity, connectedness, and diameter of the capillary pores within the binder; and the electrical resistivity of the pore fluid contained within the capillary pores.

Regarding the tortuosity, connectedness, and diameter, these could be classified as microstructural changes resulting from the hydration of the cement. The use of supplementary cementitious materials (SCM), such as fly ash or blast-furnace slag, result in further longer-term refinement to the pore structure in terms of producing a more tortuous and disconnected capillary pore network. Chloride binding effects would also serve to alter the pore structure (Midgley and Illston 1984; Suryavanshi and Scantlebury 1995) because it is known that replacement materials increase the chemical binding reaction between the cementitious component and the chloride ion (Arya et al. 1990; Dhir and Byras 1993). Concrete containing SCM would thus be expected to have a higher electrical
Table 3. $E_{a} / R_{g}$ Ratio Determined from Eq. (5); Activation Energy $E_{a}$ for Electrical Conduction Processes is Also Presented

\begin{tabular}{|c|c|c|c|c|c|c|}
\hline \multirow[b]{2}{*}{$\begin{array}{l}\text { Depth } \\
(\mathrm{mm})\end{array}$} & \multicolumn{2}{|c|}{ CEM I $42.5 \mathrm{~N}$} & \multicolumn{2}{|c|}{ CEM III/A } & \multicolumn{2}{|c|}{ CEM II/B-V } \\
\hline & $\begin{array}{c}E_{a} / R_{g} \\
(\mathrm{~K})\end{array}$ & $\begin{array}{c}E_{a} \\
(\mathrm{~kJ} / M)\end{array}$ & $\begin{array}{c}E_{a} / R_{g} \\
(\mathrm{~K})\end{array}$ & $\begin{array}{c}E_{a} \\
(\mathrm{~kJ} / M)\end{array}$ & $\begin{array}{c}E_{a} / R_{g} \\
(\mathrm{~K})\end{array}$ & $\begin{array}{c}E_{a} \\
(\mathrm{~kJ} / M)\end{array}$ \\
\hline 5 & 3,554 & 29.55 & + & + & 3,753 & 31.20 \\
\hline 10 & 4,027 & 33.48 & 4,134 & 34.37 & 3,651 & 30.35 \\
\hline 15 & 3,644 & 30.30 & 4,040 & 33.59 & 3,790 & 31.51 \\
\hline 20 & 4,167 & 34.64 & 4,053 & 33.70 & 3,725 & 30.97 \\
\hline 30 & 4,113 & 34.20 & 4,012 & 33.36 & 3,551 & 29.52 \\
\hline 40 & 4,160 & 34.59 & 3,915 & 32.55 & 3,817 & 31.73 \\
\hline 50 & 4,106 & 34.14 & 3,920 & 32.59 & 3,011 & 25.03 \\
\hline
\end{tabular}

Note: $+=$ data lost for 5-mm depth.

resistivity than a plain portland cement concrete. This is shown by the data presented in Fig. 8 as the resistivity (standardized to $25^{\circ} \mathrm{C}$ ) of the concrete mixes varies between $2-5 \mathrm{k} \Omega-\mathrm{cm}$ for the plain portland cement concrete [Fig. 8(a)], 10-18 $\mathrm{k} \Omega-\mathrm{cm}$ for the slag concrete [Fig. 8(b)], and $12-25 \mathrm{k} \Omega-\mathrm{cm}$ for the fly ash concrete [Fig. 8(c)]].

It should be emphasized that the as-measured resistivity should not be discarded, and it is important to use both standardized and as-measured data. If concrete resistivity is to be used as a parameter in the assessment of the corrosion rate for depassivated steel (see Table 3), then the as-measured value will also be important. As the temperature of the concrete decreases, the concrete becomes more resistive, and the corrosion current flowing between the anodic and cathodic sites on the rebar will decrease. Because the resistivity of the concrete will be a rate-controlling parameter, the corrosion process will become slower as the temperature decreases.

Because the electrode array can monitor changes in the electrical properties of concrete both spatially and temporally, then the movement of chloride ions from the marine environment into the cover zone can be tracked. From the electrical resistivity of the pore fluid, the resistivity of the concrete will be directly influenced by ionic concentration in the pore fluid, which would include the influence of ions entering the pore network from the external environment (e.g., chlorides, in the case of the marine environment). Resistivity will be inversely proportional to the ionic concentration; hence, as chloride gradually diffuses through the cover zone, the ionic concentration increases within the pore fluid and the measured resistance, and thus resistivity, will decrease. A resistivity gradient will be established, with resistivity increasing with depth from the exposed surface. Regular monitoring of resistivity would then allow the depth of penetration of chloride to be evaluated, becoming an early warning indicator of incipient problems.

It is evident from Fig. 8(a) that the surface $0-20 \mathrm{~mm}$ of the plain portland cement concrete exhibits very low values of resistivity, and it could be concluded that sufficient quantities of chlorides from the sea water have diffused into the cover-zone to reduce the resistivity in this region; indeed, the low resistivity values $(<5 \mathrm{k} \Omega-\mathrm{cm})$ would suggest that chlorides have penetrated through the surface 0-50 $\mathrm{mm}$ (i.e., the cover zone). The results from the slag concrete in Fig. 8(b) indicate that resistivity values over the surface 0-30 $\mathrm{mm}$ are much reduced in comparison to the values at 40-50 $\mathrm{mm}$, indicating that chlorides have penetrated through the surface $30 \mathrm{~mm}$. Results for the fly ash mix [Fig. 8(c)] indicate that it is the surface $0-20 \mathrm{~mm}$ that have been influenced by chloride ingress because values in this region are considerably reduced relative to values at greater depths. Copper/copper sulfate half-cell measurements taken on the mild-steel bars within the plain portland cement specimens (mix CEM I) were $<-350 \mathrm{mV}$ (high risk of corrosion); values for the slag mix averaged $-275 \mathrm{mV}$ (corrosion 


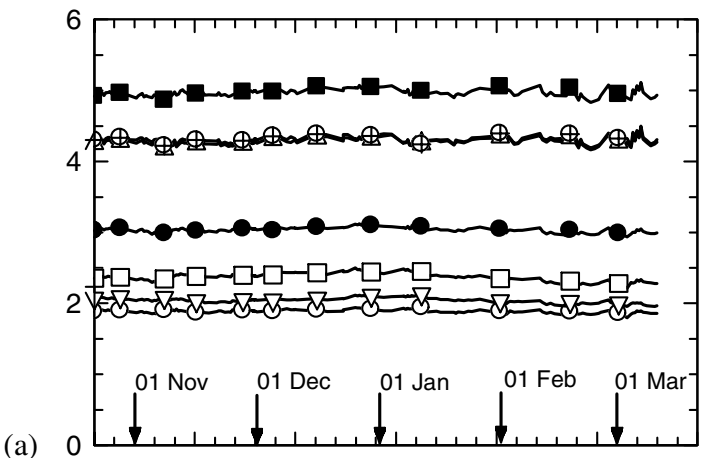

(a)

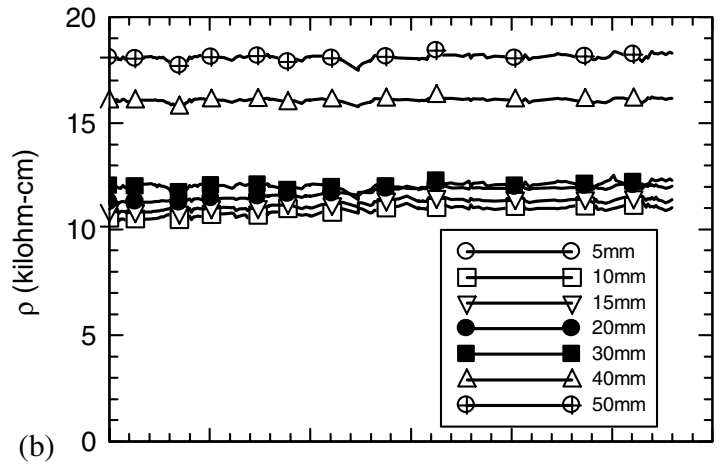

(b)

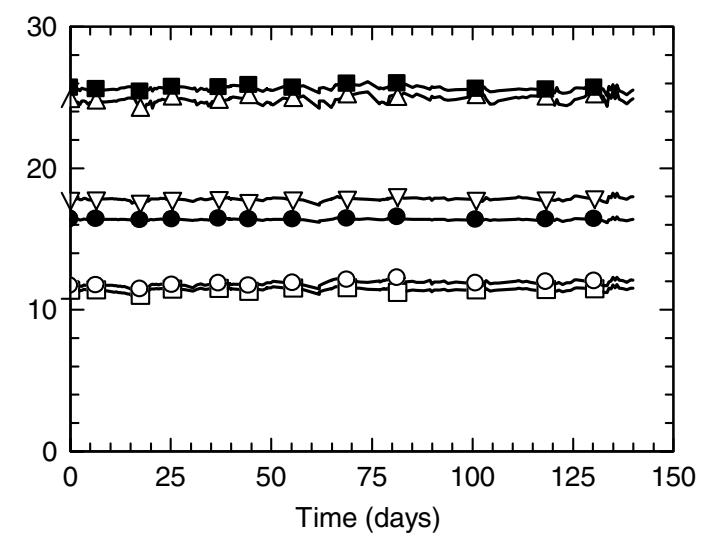

Fig. 8. Resistivity data in Fig. 5 standardized to a reference temperature of $25^{\circ} \mathrm{C}$ using $E_{a} / R_{g}$ values in Table 2 for (a) CEM I concrete mix; (b) CEM III/A concrete mix; (c) CEM II/B-V [response at $50-\mathrm{mm}$ depth has been omitted from (c) because it is considerably greater that $30 \mathrm{k} \Omega-\mathrm{cm}]$

activity uncertain), whereas measurements for the fly ash mix averaged $-160 \mathrm{mV}$ (low risk of corrosion).

Concerning the values for activation energy $\left(E_{a}\right)$ presented in Table 3 , it is interesting to note that there is no marked variation between the three different concrete mixes that generally lie within the range $29-35 \mathrm{~kJ} / \mathrm{M}$. Resistivity values, however, can change by more than an order of magnitude between the plain concrete mix and the mixes with SCM. This would indicate that concretes with SCM produce a more disconnected/tortuous pore network in comparison to plain portland cement concrete, the detailed discussion of which is outside of the scope of this paper.

\section{Concluding Comments}

The electrical resistivity of concrete is now being recognized as an important parameter that could be developed to assess concrete performance and durability. The work presented has developed a methodology for evaluating this parameter, utilizing an embedded electrode array together with a remote interrogation system to allow access to data from an office setting. Furthermore, the measurement of the electrical resistivity at discrete points allows for an integrated assessment of both spatial and temporal changes in cover-zone performance. In a broader sense, the use of such monitoring systems can provide a continuous feedback of real-time data, which can then be used to assess the current and future performance of the structure and assist in the scheduling of maintenance programs.

Data handling and processing procedures are detailed; specifically, the influence of temperature on field resistivity measurements is highlighted and a standardizing procedure presented that utilized an Arrhenius relationship between resistivity and temperature. An important aspect of the procedure entails the use of field data to evaluate the activation energy for a particular concrete and electrode pair. This ensures that temperature effects can be effectively removed from field measurements.

Regarding the presentation of resistivity measurements, it may be more informative to present the relative change in resistivity values (McCarter and Chrisp 2000) obtained at each electrode position. This could be quantified by the ratio $\rho_{t} / \rho_{o}$, where $\rho_{t}$ is the measured resistivity and $\rho_{o}$ is the resistivity obtained before exposure to chlorides (e.g., just after construction). This format of presentation would account for the natural variation in resistivity at different depths as a result of aggregate distribution around the electrodes. However, as the monitoring system detailed previously has just been installed, only resistivity values were presented.

\section{Acknowledgments}

This paper presented forms part of the concrete durability program into monitoring and improving the performance of structural concrete in bridges and in the development of performance-based testing procedures undertaken for Transport Scotland and the Engineering Science Physical Research Council, UK (Research Grants EP/G025096/1, EP/G02152X, and EP/I005846). Funding from both bodies is gratefully acknowledged. The views expressed in this paper are those of the authors and not necessarily those of Transport Scotland. The technical support of AmphoraNDT (www.amphorandt.com) is also gratefully acknowledged.

\section{References}

Alonso, C., Andrade, C., and Gonzalez, J. A. (1988). "Relation between resistivity and corrosion rate of reinforcements in carbonated mortar made with several cement types." Cem. Concr. Res., 18(5), 687-698.

Andrade, C. (2010). "Types of models of service life of reinforcement: The case of the resistivity." Concr. Res. Lett., 1(2), 73-80.

Andrade, C., Alonso, C., Arteaga, A., and Tanner, P. (2000a). "Methodology based on the electrical resistivity for the calculation of reinforcement service life." Proc., 5th Int. CANMET/ACI Conf. on Durability of Concrete (Supplementary Papers), American Concrete Institute, Farmington Hills, MI, 899-915.

Andrade, C., Alonso, C., and Goni, S. (1993). "Possibilities for electrical resistivity to universally characterise mass transport processes in concrete." Proc., Concrete 2000 Conf., R. K. Dhir and M. R. Jones, eds., E\&FN Spon, Dundee, UK, 1639-1652.

Andrade, C., Gonzalez-Gasca, C., and Torrent, R. (2000b). "Suitability of the torrent permeability tester to measure air-permeability of concrete." Proc., 5th Int. CANMET/ACI Conf. on Durability of Concrete, Vol. 1, American Concrete Institute, Farmington Hills, MI, 301-317.

Arya, C., Buenfeld, N. R., and Newman, J. B. (1990). "Factors influencing chloride-binding in concrete." Cement Concrete Res., 20(2), 291-300.

Atkinson, A., and Nickerson, A. K. (1984). "The diffusion of ions through water-saturated cement.” J. Mater. Sci., 19(9), 3068-3078. 
Basheer, P. A. M. (1993). "A brief review of methods for measuring the permeation properties of concrete in situ." Proc. Inst. Civ. Eng.: Struct. Build., 99(1), 74-83.

Blight, G. E., and Lampacher, B. J. (1995). "Applying covercrete absorption test to in-situ tests on structures." J. Mater. Civ. Eng., 7(1), 1-8.

Brite EuRam III (European Union). (1998). "Duracrete-Modelling of degradation." Rep. BE95-1347/R4-5, Taywood Engineering Ltd., Middlesex, UK.

British Standards Institution (BSI). (1996). "Testing concrete. Recommendations for the determination of the initial surface absorption of concrete." BS 1881-208, London.

British Standards Institution (BSI). (2000a). "Cement—Part 1: Composition, specifications and conformity criteria for common cements." BS-EN 197-1, London.

British Standards Institution (BSI). (2000b). "Concrete: Specification, performance, production and conformity." BS EN 206-1, London.

British Standards Institution (BSI). (2005). "Fly ash for concrete-Part 1: Definition, specifications and conformity criteria." BS-EN 450-1, London.

British Standards Institution (BSI). (2006a). "Concrete-Complementary British standard to BS EN 206-1,-Part 1: Method of specifying and guidance for the specifer.” BS 8500-1, London.

British Standards Institution (BSI). (2006b). "Ground granulated blast furnace slag for use in concrete, mortar and grout-Part 1: Definitions, specifications and conformity criteria." BS-EN 15167-1, London.

British Standards Institution (BSI). (2011). "Testing concrete. Method for determination of water absorption." BS 1881-122, London.

Broomfield, J. P. (1997). Corrosion of steel in concrete, E\&FN Spon, London.

Buenfeld, N. R., Davies, R. D., Karimi, A., and Gilbertson, A. L. (2008). "Intelligent monitoring of concrete structures." Construction Industry Research and Information Association (CIRIA) Rep. C661, CIRIA, London, UK, 150.

Castellote, M., Andrade, C., and Alonso, M. C. (2002). "Standardization, to a reference of $25^{\circ} \mathrm{C}$, of electrical resistivity for mortars and concretes in saturated or isolated conditions." ACI Mater. J., American Concrete Institute, Farmington Hills, MI, 99(2), 119-128.

Chrisp, T. M., McCarter, W. J., Starrs, G., Basheer, P. A. M., and Blewett, J. (2002). "Depth related variation in conductivity to study wetting and drying of cover-zone concrete." Cem. Concr. Compos., 24(5), 415-427.

Classie, P. A., Elsayad, H. I., and Shaaban, I. G. (1999). "Test methods for measuring fluid transport in cover concrete.” J. Mater. Civ. Eng., 11(2), 138-143.

Dhir, R. K., and Byars, E. A. (1993). "PFA concrete: Chloride diffusion rates." Mag. Concr. Res., 45(162), 1-9.

Dhir, R. K., Hewlett, P. C., and Chan, Y. N. (1987). "Near-surface characteristics of concrete: Assessment and development of in situ test methods." Mag. Concr. Res., 39(141), 183-195.

Figg, J. W. (1973). "Methods for measuring the air and water permeability of concrete." Mag. Concr. Res., 25(85), 213-219.

Fiore, S., Polder, R. B., and Cigna, R. (1996). "Evaluation of the concrete corrosivity by means of resistivity measurements." Proc., 4th Int. Symp. on Corrosion of Reinforcement in Concrete Construction, C. L. Page, P. B. Bamforth, and J. W. Figg, eds., Royal Society of Chemistry, Cambridge, UK, 273-282.

Garboczi, E. J., and Bentz, D. P. (1992). "Computer simulation of the diffusivity of cement-based materials." J. Mater. Sci., 27(8), 2083-2092.

Gowers, K. R., and Millard, S. G. (1999). "Measurement of concrete resistivity for assessment of corrosion severity of steel using Wenner technique." ACI Mater. J., 96(5), 536-541.

Hall, C., and Yau, M. H. R. (1987). "Water movement in porous building materials-IX: The water absorption and sorptivity of concretes." Build. Environ., 22(1), 77-82.
Langford, P., and Broomfield, J. P. (1987). "Monitoring the corrosion of reinforcing steel." Constr. Repair, 1(2), 32-36.

Lopez, W., and Gonzalez, J. A. (1993). "Influence of degree of saturation on the resistivity of concrete and the corrosion rate of steel reinforcement." Cem. Concr. Res., 23(2), 368-376.

McCarter, W. J. (1993). "Influence of surface finish on sorptivity of concrete." J. Mater. Civ. Eng., 5(1), 130-136.

McCarter, W. J., and Brousseau, R. (1990). "The A.C. response of hardened cement paste." Cem. Concr. Res., 20(6), 891-900.

McCarter, W. J., and Chrisp, T. M. (2000). "Monitoring water and ionic penetration into cover-zone concrete." ACI Mater. J., 97(6), 668-674.

McCarter, W. J., Emerson, M., and Ezirim, H. (1996). "Properties of concrete in the cover zone: Water penetration, sorptivity and ionic ingress." Mag. Concr. Res., 48(176), 149-156.

McCarter, W. J., Starrs, G., Kandasami, S., Jones, M. R., and Chrisp, M. (2009). "Electrode configurations for resistivity measurements on concrete." ACI Mater. J., 106(3), 258-264.

Meletion, C. A., Mang, T., and Bloomquist, D. (1992). "Development of a field permeability test apparatus and method for concrete." ACI Mater. J., 89(1), 83-89.

Midgley, H. G., and Illston, J. M. (1984). "The penetration of chlorides into concrete." Cem. Concr. Res., 14(4), 546-558.

Millard, S. G., and Gowers, K. R. (1992). "Resistivity assessment of in-situ concrete: The influence of conductive and resistive surface layers." Proc. Inst. Civ. Eng.: Struct. Build., 94(4), 389-396.

Nanukuttan, S. V., Basheer, P. A. M., McCarter, W. J., Basheer, L., and Robinson, D. J. (2008). "Full-scale marine exposure tests on treated and untreated concrete: Initial 7-year results." ACI Mater. J., 105(1), $81-87$.

Polder, R. B., and Peelen, W. H. A. (2002). "Characterisation of chloride transport and reinforcement corrosion in concrete under cyclic wetting and drying by electrical resistivity." Cem. Concr. Compos., 24(5), 427-435.

Poursaee, A., and Weiss, W. J. (2010). "An automated electrical monitoring system (AEMS) to assess property development in concrete." Automation Constr., 19(4), 485-490.

Rajabipour, F., and Weiss, J. (2007). "Electrical conductivity of drying cement paste." Mater. Struct., 40(10), 1143-1160.

Rajabipour, F., Weiss, J., Shane, J. D., Mason, T. O., and Shah, S. P. (2005). "Procedure to interpret electrical conductivity measurements in cover concrete during rewetting." J. Mater. Civ. Eng., 17(5), 586-594.

Raupach, M., and Schiessl, P. (2000). "Monitoring corrosion risk in concrete structures-review of 10 years experience and new developments." Proc., 5th CANMET/ACI Int. Conf. on Durability of Concrete, Vol. 1, The American Concrete Institute, Farmington Hills, MI, 9-34.

Shi, C. (2004). "Effect of mixing proportions of concrete on its electrical conductivity and the rapid chloride permeability test (ASTM C1202 or ASSHTO T277) results." Cem. Concr. Res., 34(3), 537-545.

Suryavanshi, A. K., and Scantlrbury, J. D. (1995). "Pore size distribution of OPC and SRPC mortars in the presence of chlorides." Cem. Concr. Res., 25(5), 980-988.

Whittington, H. W., McCarter, J., and Forde, M. C. (1981). "The conduction of electricity through concrete." Mag. Concr. Res., 33(114), 48-60.

Wilson, M. A., Taylor, S. C., and Hoff, W. D. (1998). "The initial surface absorption test (ISAT): An analytical approach.” Mag. Concr. Res., 50(2), June, 179-185.

Yunovich, M., Thompson, N. G., Balvanyos, T., and Lave, L. (2001). "Highway bridges: Appendix D." Dept. of Transport and Federal Highway Authority 〈http://www.corrosioncost.com/pdf/highway.pdf〉 (May 1, 2011). 